\title{
Preface
}

\section{Ethics and the Sports Medicine Physician}

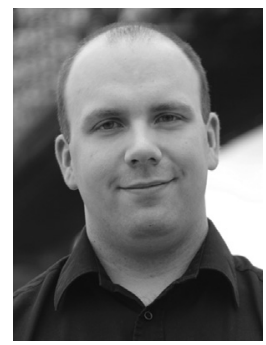

Stephen R. Thompson, MD, MEd, FRCSC Editor

It is clear that whoever is a physician must be altogether a philosopher.

- Galen

The practice of sports medicine enables many unique opportunities to the physician but also results in several unique challenges. One particular challenge is practicing in an ethical fashion. There are multiple scenarios that occur in the office, in the training room, and on the field that result in ethical dilemmas. Navigating these issues is not always easy, and, often, there is no clear direction to take.

The purpose of this issue is to provide the basic ethical framework to the sports medicine physician to enable them to tackle these challenges head on. We have been fortunate to have contributions from a wide array of authors. Several are physicians who practice at the highest levels of professional sports, while others are philosophers, ethicists, and attorneys.

To begin, Dr Devit lays the groundwork in his article on "Fundamental Ethical Principles in Sports Medicine." Next, Dr Malcolm provides guidance on how to handle patient confidentiality in a sports medicine practice in his article on "Confidentiality in Sports Medicine." Invariably, caring for athletes results in a conflict of interest owing to the "patient-physician-team" triad. Dr Tucker leans on his many years of professional team medical coverage on how to handle these conflicts in his article on "Conflicts of Interest in Sports Medicine."

Similarly, within the professional environment, the physician can experience the unique challenges associated with analgesic use to mask pain and improve performance. Dr Matava, also a professional team physician, outlines the different regulations and best practices in his article, "Ethical Considerations for Analgesic Use in Sports Medicine." 
Ethics and the law often coexist, and Professor Koller provides a comprehensive review of important ethical and legal aspects as they relate to the practice of sports medicine in her article, "Team Physicians, Sports Medicine, and the Law: An Update." Following this, Professor McNamee, Professor Partridge, and Professor Anderson detail their thinking of ethics surrounding concussion care in their very seminal article, "Concussion Ethics and Sports Medicine."

Closely related to this are issues of standards of care in professional athletes who are often willing to have "substandard" care for better short-term performance but to the detriment of their long-term health. Drs Poma, Sherman, Spence, Brenner, and Bal use their combined medical and legal experience to propose a series of guidelines to define a standard of care in their article, "Rethinking the Standard of Care in Treating Professional Athletes."

Finally, there is a set of very unique ethical issues within sports medicine that warrants further discussion. Drs Tan, Calitri, Bloodworth, and McNamee discuss the ethics surrounding eating disorders in gymnasts in their article, "Understanding Eating Disorders in Elite Gymnastics: Ethical and Conceptual Challenges." Professor Camporesi then provides a thought provoking article on the ethics of concussion management in her article, "Ethics of Regulating Competition for Women with Hyperandrogenism." Last, we would never advance without research into our practice, and Drs Steward and Reider detail the important ethical principles of research in the article, "The Ethics of Sports Medicine Research."

I am indebted to this outstanding multidisciplinary group of individuals, who have provided insightful and clear discussion on this frequently encountered but rarely taught subject. As Galen wrote, “...that the best physician is also a philosopher.”

Stephen R. Thompson, MD, MEd, FRCSC The University of Maine Eastern Maine Medical Center 925 Union Street, Suite 3 Bangor, ME 04401, USA 